\title{
COVID Infodemic is turning public into Covidiots: What can be done?
}

\section{Neeta Kumar ${ }^{1}$, Sanjiv Kumar ${ }^{2}$}

${ }^{1}$ Professor Faculty of Dentistry, Jamia Millia Islamia, New Delhi; ${ }^{2}$ Chairperson, Indian Academy of Public Health, Indian Public Health Association, Former ED, NHSRC and Senior Advisor, UNICEF

\section{Corresponding Author}

Dr Sanjiv Kumar, M 15, Second Floor, South Extension Part 2, New Delhi 110049.

E Mail ID: drsanjivkumardixit@gmail.com

\section{Citation}

Kumar N, Kumar S. COVID Infodemic is turning public into Covidiots: What can be done?. Indian J Comm Health. 2021;33(2):236-238. https://doi.org/10.47203/IJCH.2021.v33i02.001

Source of Funding: Nil Conflict of Interest: None declared

\section{Article Cycle}

Received: 10/06/2021; Revision: 18/06/2021; Accepted: 25/06/2021; Published: 30/06/2021

This work is licensed under a Creative Commons Attribution 4.0 International License.

An unprecedented pandemic of Corona Virus Disease 2019 (COVID 19) has overwhelmed the health systems of countries across the world. The government and other scientific bodies are providing authentic information to educate the public and promote desirable behavior to prevent new infections and reduce deaths. COVID-19 pandemic is the first in human history in which social media and new digital technologies are being used as key tools to inform the public. However, there is a lot of misinformation also being spread through these channels. Misinformation is false, inaccurate, or misleading information that is communicated regardless of an intention to deceive. Access to social media has improved substantially, which has contributed to spread of misinformation. Today, anybody can write anything on social media such as Twitter, WhatsApp, Facebook, TikTok, YouTube etc without any evidence or falsely attribute the wrong information to well-known experts or renowned institutions. They may be doing it to support their own biases or malign the government purposefully or innocently without checking authenticity. The number of mentions in media for Ebola were 11.1 million, for MERS, 23.2 million, HIV, 40 million, SARS, 56.2 million and COVID19 it has crossed 1.1 billion.(3) A google search for COVID 19 on 08 June 2021 gave 5340 million hits compared to 216 million for a much older disease HIV/AIDS. This editorial is an attempt to help spot the false information and deal with it.

\section{The epidemic of misinformation}

The epidemic of misinformation (Infodemic) is far more virulent than the COVID19 pandemic. U.N. SecretaryGeneral Antonio Guterres stated that the world is not only fighting the "common enemy" of the coronavirus "but our enemy is also the growing surge of misinformation" about
COVID-19 disease. To overcome the virus, "we need to urgently promote facts and science" and "promote hope and solidarity over despair and division." (4) The UN has recognized this problem and is actively engaged in helping countries in tackling it. "We're not just fighting an epidemic; we're fighting an infodemic," and fake news "spreads faster and more easily than this virus." said Tedros Adhanom Ghebreyesus, Director-General of the World Health Organization.(5) The problem is so important to deal with that a new discipline 'Infodemiology' is born to study and address it.

The government of India has been actively addressing the misinformation. An advisory has been issued to curb it early during the pandemic (20 March 2020) asking social media companies to voluntarily curb fake news and misinformation related to the coronavirus on their platforms.(6) With exponential growth of social media and its users it has become the main source of information. Unfortunately, the information on social media reaches people fast as it takes only a few hours for any information to become viral. According to Statistica, social media users in India increased from 142.2 in 2015 to 376.1 million in 2020.(7) The information shared on social media also spreads to non-users through word of mouth. Facebook remains a popular choice among social media users but new social media platforms such as Chinese TikTok (188 million) has outpaced Facebook (176 million) downloads in Jan-Mar 2019.(8)

Misinformation contributes to stigma and facilitates transmission of disease

Misinformation creates fear among public and contributes to increase in super spreader individuals and events(9). It impacts the whole populations, those without disease do not follow preventive behaviour, those with symptoms 
may not report to health facilities early and continue to spread infections, contacts are not traced and do not report to authorities, those quarantined run away, those with severe symptoms report late. These result in spread of infection and increase mortality. The media can and should play an important role in empowering people to practice preventive measures by providing authentic information. The media is full of reports of adverse outcomes of false information causing panic reaction and harming the suspected cases such as Times of India on just one day (02 April 2020) reported five instances of violence due to stigma, fueled by misinformation on COVID19. A man shot a woman for informing about visitors in a neighbour's family in Alipur village of Mainpuri; a suspected case of COID19 was found dead in Bibikulum Kerala; a deaf and dumb man was abandoned by his family at AlIMS Raipur, however the report came negative. In Indore, a health screening team was attacked and Police men were assaulted when they went to trace Tablighi Jamaat gathering contacts.(9) The fear and stigma against COVID 19 patients, their families, healthcare providers, spreaders etc. is wide spread. The ongoing global media frenzy has exacerbated risks of infection and deaths from COVID19

False Information: The false information may be completely unfounded designed to make people believe something false, baseless or without any evidence to support it. The person sharing false information in social media or forwarding it innocently without confirming its authenticity or may be doing it purposely to support and promote one's own biased views. There may be an effort to present it in a sensational way to generate viewers' interest and get it further forwarded. It may be biased information aimed to convince readers to a certain ideology. Those who spread such information may claim that it is factually accurate, just because they don't agree with another point of view. Fake news is a type of misinformation and is not new. But, what is new is the ease with which it spreads on a massive scale. The problem is that most people don't check the source of the information or do not even read it before forwarding it. At times it's hard to identify the source of information and assess its accuracy. They are also guilty of inadvertently spreading misinformation.

Misinformation During COVID19: The government of India and WHO also acknowledge, there is a considerable false information around and dispels these through 'Myth Busters' at MOHFW's website on COVID19.(10) So does WHO prominently at their website.(11) The misinformation and myths have a negative impact on the control and preventive measures.

One can also fact check about COVID19 on other websites such as https://www.mohfw.gov.in/, one can post a statement about COVID19 on Snopes website (https://www.snopes.com/collections/new-coronaviruscollection/ ), to find out if a statement is true or false. It also has many facts about COVID19, they have already responded to. One can also contact a government COVID helpline numbers.(12)

The Impact of misinformation during an epidemic: Fake news does affect the behavior of the people. It encourages people to invent excuses, dismiss correct information, exaggerate the truth, and spread rumors. This can create anxiousness in society causing people to become cynical and unsure of who to do and whom to trust. Misinformation and fake news can also harm any institution. In an epidemic it may lead to

1. Panic, fear and paralysis to act

2. Loss of faith in scientific evidence based interventions

3. False sense of security which may increase transmission of diseases, delay in seeking treatment and increase the risk of severe disease, lifelong disability or death.

4. Behaviour that increases the risk of spread of disease

5. Diversion of attention of authorities to debunking myths and clarifying false information

6. Stress and social isolation leading to or aggravating mental health problems

Some of the people exposed to false information may mistrust correct information. This can damage a society's learning culture and hampers efforts in controlling and managing an epidemic such as COVID19.

Identify misinformation. (13)

The misinformation is more likely to catch attention, look believable and may be deliberately planted. One should approach misinformation rationally and critically. Separating fact from fiction may seem daunting. But getting to the truth is always important - even if it's not what one wants to hear! The following six steps will help to get to the truth and catch the lies:

1. Check the Source: Look for the source of information. Confirm that the source assigned owns it up. One can check with the person or an institution to whom it is assigned, check on their website, if not available there, contact them through email or telephone (usually available under 'Contact Us' at their website). Recently a report assigned to a renowned US public health institution with their logo on it was going viral in professional WhatsApp groups, till someone checked and the institution denied anything to do with that report. If it is published, find out about the publisher - is it a well-known journal and publisher or is it someone's personal blog? If it gives a Uniform Resource Locator (URL) link of the page, check the link. It may not exist or look too suspicious to believe.

If the information is told by another person, consider his reputation and professional experience. There are many 'self-styled' public health experts on electronic media. In today's world of specialization, you will not consult a cardiologist for a gynecology problem. Similarly, we need to know what aspects are within their areas of expertise. 
You may look at trusted online sources like websites of WHO, UNICEF, MoHFW or other reputed institutions.

2. Check if any other reputed media house has reported this information: Check whether the story has been picked up by other well-known media house(s). We know that most media houses have strong political leanings. Some are known to criticize everything the government does and others are known to support everything, it does. These are like outliers in statistics and their views should be ignored to get a balanced perspective. Stories from reputed organizations like Press Trust of India, ministry websites, Reuters, CNN and the BBC are checked and verified. If the information you have isn't from a wellknown source like these, there's a possibility of it being fake.

3. Analyze the Evidence: A credible information may include quotes of well-known experts, survey data and official statistics. If these are missing or the source is an unknown person, it may be false. Does the evidence prove that something definitely happened? Is it an opinion and not a fact? Or, have the facts been "twisted" to back up a particular viewpoint such as 'government has failed'?

4. Look for Fake Images or Fake Research: Modern editing software has made it easy for people to create fake images that look real. In fact, only some of us can tell whether the images we are looking at are fake. However, in fake images there are some warning signs you can look for. Strange shadows on the image, for example, or jagged edges around a figure. If you still have doubts, you can use tools such as 'Google Reverse Image Search' to check whether the image has been altered or used in the wrong context, similarly, a research or an expert's statement or part of it may be used out of context.

5. Plausibility: You must use your common sense! If an information sounds unbelievable, it probably is. Bear in mind that fake news or misinformation thrives on your biases or fears. And, remember, just because a story sounds right and true, doesn't mean that it is. If a politician is giving away a million doses of a medicine (such as hydroxychloroquine) to other countries does not mean it is effective. Equally, just because your friend believes that a home remedy is $100 \%$ effective in preventing or curing COVID, doesn't mean it's true.

Authorities must promptly act to curb false information If the information is found false, authorities must promptly step in to provide correct in formation and take action against those providing false information under Epidemic Act 1897 and National Disaster Management Act, 2005.

\section{Conclusion}

It is very important to understand how wrong information starts, how it spreads, its impact, and how it can be contained. Misinformation refers to deliberate untruths or partial truths. Misinformation has a negative impact on people's behavior and an adverse impact on prevention, control and treatment of cases in an epidemic. It contributes to creating stigma, marginalizing those who need help the most, their care providers, adversely impacting service delivery and creates mistrust hampering epidemic containment. Hence addressing misinformation is a vital components of the strategy of epidemic control. This can be done by actively looking for and addressing misinformation by following five simple steps; One, Check the source; Two, check if any reputed media house has covered it; Three, Examine the evidence, Four, look for fake pictures and fake research, and Five, Is it plausible? If the information is found false, authorities must step in to provide correct information and take action against those spreading false information under Epidemic Act 1897 and National Disaster Management Act, 2005.

\section{References}

1. WHO Corona Disease (COVID 19 Dash Board available at https://covid19.who.int/ [Accessed 25 Jun 2021].

2. Ministry of Health and Family Welfare, Government of India, New Delhi. Available at https://www.mohfw.gov.in/ [Accessed 25 Jun 2021].

3. World Economic Forum Report. 2 Ways to minimize the impact of COVID-19 on vulnerable communities. available at https://www.weforum.org/agenda/2020/03/covid19-minimizeimpact-on-vulnerable-communities/ [Accessed 25 Jun 2021]

4. UN Chief says misinformation about COVID 19 in new enemy available at https://abcnews.go.com/US/wireStory/chiefmisinformation-covid-19-enemy-69850124. [Accessed 25 Jun 2021].

5. WHO. UN tackles 'infodemic' of misinformation and cybercrime in COVID-19 crisis available at https://www.un.org/en/uncoronavirus-communications-team/un-tackling\%E2\%80\%98infodemic\%E2\%80\%99-misinformation-and-

cybercrime-covid-19. [Accessed 25 Jun 2021]

6. Ministry of Electronics and Information Technology, Advisory to Curb false news/ misinformation on Corona virus 20 March 2020. Available https://meity.gov.in/writereaddata/files/advisory to curb false news-misinformation on corona_virus.pdf [Accessed 25 Jun 2021].

7. https://www.statista.com/statistics/278407/number-of-socialnetwork-users-in-india/

8. https://economictimes.indiatimes.com/tech/internet/battlegroun d-india-tiktok-bests-facebook-in-round1 /articleshow/69316576.cms

9. Kumar S. Leadership through the eyes of a public health professional: A journey of 43 years. Indian J Public Health. $2020 \mathrm{Jul}-$ Sep;64(3):209-215. doi: 10.4103/ijph.IJPH_512_20. PMID: 32985419.

10. Ministry of Health and Family Welfare. Myth-Busters available at https://www.mygov.in/covid-19. [Accessed 26 Jun 2021]

11. WHO Corona Virus Disease (COVID-19) Advice for the public https://www.who.int/emergencies/diseases/novel-coronavirus2019/advice-for-public/myth-busters . [Accessed 26 Jun 2021].

12. Government COVID Helpline numbers available at https://www.mohfw.gov.in/pdf/coronvavirushelplinenumber.pdf [Accessed 25 Jun 2021]

13. Mind Tools. How to spot real and fake news? Available at https://www.mindtools.com/pages/article/fake-news.htm [Accessed 26 Jun 2021] 